Article

\title{
The Genetic Variability of Floral and Agronomic Characteristics of Newly-Bred Cytoplasmic Male Sterile Rice
}

\author{
Raafat El-Namaky ${ }^{1,2}$ (D) \\ 1 AfricaRice, Senegal Regional Center, B.P. 96 Saint Louis, Senegal; relnamaky@gmail.com; \\ Tel.: +20-11-1257-6417 \\ 2 Rice Research \& Training Center (RRTC), 33717 Sakha Kafr Sheikh, Egypt
}

Received: 2 April 2018; Accepted: 7 May 2018; Published: 11 May 2018

\begin{abstract}
Male sterility enabled commercialization of heterosis in rice but low seed set remains a constraint on hybrid dissemination. We evaluated $216 \mathrm{~F}_{6}$ maintainer lines for agronomic and floral characteristics in augmented design and selected 15 maintainer lines, which were testcrossed with IR58025A. Five backcrosses were conducted to transfer cytoplasmic male sterility (CMS) to select maintainer lines. Newly-bred $\mathrm{BC}_{5: 6} \mathrm{CMS}$ lines were evaluated for outcrossing rates and agronomic characteristics. There were highly significant differences among $216 \mathrm{~F}_{6}$ maintainer lines for characteristics whose genotypic variance was higher than environmental variance. The phenotypic coefficient of variation was almost the same as the genotypic coefficient of variation, indicating that most phenotypic variation was due to genetics. There were highly significant differences among CMS lines for number of days to $50 \%$ flowering and maturity; stigma exertion; panicle exertion, length and weight; spikelet fertility; tillers per plant; plant height; grains per panicle; grain yield per plant; and 1000-grain weight, but not for pollen and panicle sterility during dry and wet seasons. Three CMS lines (CMS3, CMS12, and CMS14), exhibited high outcrossing rates (56.17\%, 51.42\% and $48.44 \%$, respectively), which had a highly significant, positive correlation with stigma exertion (0.97), spikelet opening angle (0.82), and panicle exertion (0.95).
\end{abstract}

Keywords: Oryza sativa; CMS lines; genetic variability; hybrid seed; maintainer lines; outcrossing rate; rice

\section{Introduction}

Rice (Oryza sativa) is a staple food in West Africa, where its demand keeps increasing due to population growth. Hence, there is an urgent need to identify high-yield rice cultivars that fulfill this demand locally [1]. Hybrid rice can contribute to food security by increasing the availability of staple food for consumption by farm households and increasing on-farm income through higher grain yield [2]. Success in breeding and growing hybrid rice commercially in China has caused great interest among rice breeders throughout the world. However, the natural outcrossing rate in rice cultivars is extremely low and hybrid seed production, using male sterility or gametocides, presents some difficulties. Increasing the potential outcrossing rate would facilitate the use of hybrids in other areas of the world.

The availability of both stable cytoplasmic male sterility (CMS) and fertile restoration system is very important for commercial exploitation of heterosis in any crop. The advantage of cytoplasmic male sterility (CMS) is that the pollen in the male sterile line is aborted, while the female organ is normal. This allows stigma cross-pollination from other plants to generate heterozygous seeds [3]. Stigma exertion, panicle exertion, and angle of opened lemma and palea of male sterile lines are the 
key determinants of outcrossing in hybrid rice seed production [4,5]. The exerted stigma can bypass the physical barrier of glumes between the pollen of restorer lines and the stigma of CMS lines in rice. Exerted stigma of rice seems to improve the outcrossing rate of the sterile lines [6,7]. Agronomic traits should also be taken into account for achieving heterosis for grain yield. Hence, developing CMS lines with good floral and agronomic traits is necessary for hybrid rice breeding.

The floret of $O$. sativa is a terminal panicle of perfect flowers. Each spikelet has a branched stigma, six stamens, and two lodicules. At blooming, the flowers open rapidly. The flowers remain open for 1-3 $\mathrm{h}$ and close after anthesis, but never reopen. Some floral characteristics, such as stigma size, stigma exertion, and flower opening duration, affect the rate of outcrossing in rice. Usually the stigma remains inside the glumes during and after anthesis. In some cultivars, some stigmas remain outside the glumes after anthesis and fertilization. The rate of exerted stigma, which ranges from 0 to $90 \%$, is correlated with stigma length. Stigma length ranges between 0.4 and $1.6 \mathrm{~mm}$ [8-12]. The duration of receptivity is variable and may exceed five days.

Achieving improved floral and agronomic traits in the maintainer line is the first step in developing new CMS lines with desirable traits through the backcross breeding method. Evaluation of newly developed CMS lines of rice for their morphological and floral traits to determine variation among genotypes is essential so that phenotypically excellent lines can be exploited for the development of rice hybrids to identify genotypes with desirable morphological and floral characteristics [5]. The genetics of stigma exertion is quantitative and influenced by dominance effects, followed by additive effects [13]. The genetic advance for stigma length and spikelet length appears to be greater than that of other floral characteristics, thus stigma exertion could be improved by selection in early generations.

In 2010, AfricaRice began breeding hybrid rice using both cytoplasmic male sterile and environmental genetic male sterile systems $[14,15]$. In this study, 216 maintainer lines were evaluated for their floral and agronomic characteristics. Five successful backcrosses with 15 selected maintainer lines led to developing 15 new CMS lines. The 15 new CMS were evaluated for outcrossing rates and agronomic characteristics along with popular CMS lines as checks. The main objective of this research was to study the genetic variability of some floral and agronomic traits of newly bred CMS lines in rice.

\section{Materials and Methods}

This research was carried out at AfricaRice Regional Center, Saint Louis, Senegal from 2013 to 2017, as described briefly in Figure 1 . The study included 216 maintainer lines $\left(\mathrm{F}_{6}\right)$ derived from four breeding populations, namely V20B/IR72793B (46 lines), IR80561B/IR72793B (54 lines), IR93561B/IR58025B (65), and IR93561B/IR68897B (51 lines), which were evaluated for agronomic and floral characteristics using an augmented design with 12 blocks. Each block contains 18 lines and two popular maintainers IR68897B (early maturity) and IR58028B (late to medium maturity) as checks. Each line was transplanted in four rows $3 \mathrm{~m}$ long and with a spacing of $20 \times 20 \mathrm{~cm}$. The experiment used a recommended package of crop husbandry practices during plant growth. Data were recorded on five random plants within each plot for number of days to 50\% flowering (DAF), number of days to maturity (DAM), stigma exertion (SE, \%), panicle length (PnL), panicle weight (PnW), spikelet fertility (SF, \%), panicle exertion (PnE, \%), tillers per plant (NPT), plant height (PH) grains per panicle (NGP), grain yield per plant (GYP), and 1000-grain weight (GW). 


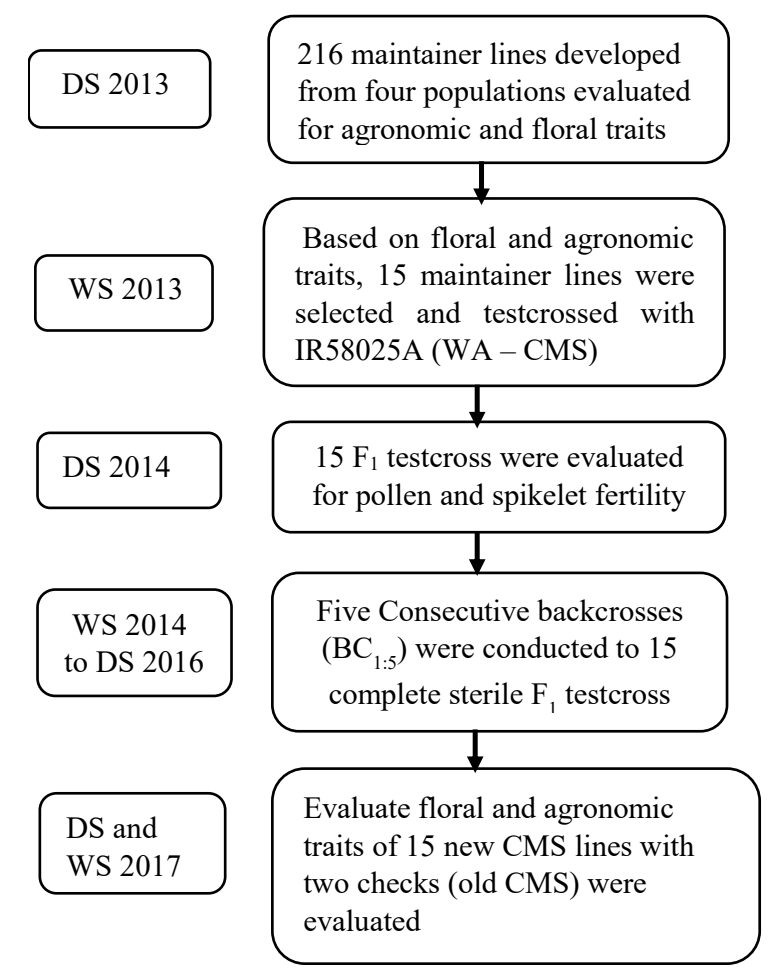

Figure 1. Scheme of evaluation of maintainer lines and developing new cytoplasmic male sterility (CMS) lines in dry (DS) and wet (WS) seasons at Saint Louis, Senegal.

\subsection{Backcrossing and Derived Offspring Assessment}

Out of 216 maintainer lines evaluated for floral and agronomic traits, 15 lines were selected and testcrossed with IR58025A (a popular WA CMS used for commercial production in many countries). Five consecutive backcrosses $\left(\mathrm{BC}_{1: 5}\right)$ were conducted to complete the transfer of cytoplasmic male sterile (CMS) to selected maintainer lines. The backcross offspring and its parent were transplanted side by side on two or three rows based on the seeds available. Pollen fertility (POF), DAF, and phenotypic acceptability (PAC) were evaluated for all offspring and their parents. The new CMS lines derived from $\mathrm{BC}_{5: 6}$ were evaluated for agronomic and floral characteristics.

\subsection{Outcrossing Experiment}

The 15 newly-bred CMS lines derived from $\mathrm{BC}_{5: 6}$, plus two old CMS lines and their respective maintainers, were evaluated for outcrossing rates and agronomic characteristics during the dry and wet seasons in 2017. The maintainer of each line was sown four days after the male sterile lines to optimize the synchronization of flowering. The CMS and their maintainer were evaluated in a randomized complete block design with three replications. The CMS lines were transplanted in six rows, while their respective maintainer used two rows of $3 \mathrm{~m}$ long; i.e., 6:2 row ratio. Flag leaf cutting was done for all CMS before heading to facilitate outcrossing. Correlation coefficients between floral characteristics and outcrossing rates were estimated using SPSS version 16 for Windows [16].

Data were recorded on five plants per plot for DAF, DAM, SE, PnE (\%), PnL, PnW, SF, NPT, PH, NGP, GYP, and GW. About 15 spikelets from the freshly emerged panicles of at least 10 plants were collected and examined under a microscope with $1 \%$ iodine potassium iodide (IKI) solution for pollen sterility assessment [17]. For this purpose, panicles emerging from the sheath were bagged with paper bags prior to anthesis to prevent cross-pollination. Data recording was done according to the standard evaluation system for rice [18]. For glume angle, at the time of flowering, three well-opened florets of the primary panicle were collected. The angle of the opened floret was measured using a protractor. The stigma exertion was calculated by the ratio of spikelets with exerted stigma to the total number 
of spikelets and expressed as a percentage. Bagged panicles were also harvested to assess spikelet percentage. Digital cameras were used to take photos every $4 \mathrm{~min}$ to estimate the flowering time of each CMS lines.

\section{Estimation of phenotypic and genotypic variances:}

The phenotypic and genotypic coefficients of variation were computed as per the methods suggested by $[19,20]$ :

$$
\begin{gathered}
\text { Genotypic variance }\left(\sigma_{\mathrm{g}}^{2}\right)=\left(\mathrm{Ms}_{\mathrm{g}}-\mathrm{Ms}_{\mathrm{e}}\right) / \mathrm{r} \\
\text { Environmental variance }\left(\sigma_{\mathrm{e}}^{2}\right)=\mathrm{Ms}_{\mathrm{e}}
\end{gathered}
$$

where $\mathrm{Ms}_{\mathrm{g}}$ and $\mathrm{Ms}_{\mathrm{e}}$ are the mean sum of squares for the genotypes and error in the analysis of variance, respectively, and $\mathrm{r}$ is the number of replications.

The phenotypic variance was estimated as the sum of the genotypic and environmental variances:

$$
\text { Phenotypic variance }\left(\sigma_{\mathrm{ph}}^{2}\right)=\sigma_{\mathrm{g}}^{2}+\sigma_{\mathrm{e}}^{2}
$$

\section{Estimation of genotypic and phenotypic coefficient of variability:}

The genotypic and phenotypic coefficients of variability were calculated according to the following formulae:

$$
\begin{aligned}
& \text { Genotypic Coefficient of Variation }(\mathrm{GCV})=\left(\sigma_{\mathrm{g}} / \text { grand mean }\right) \times 100 \\
& \text { Genotypic Coefficient of Variation }(\mathrm{PCV})=\left(\sigma_{\mathrm{ph}} / \text { grand mean }\right) \times 100
\end{aligned}
$$

where $\sigma_{\mathrm{g}}$ and $\sigma_{\mathrm{ph}}$ are the genotypic and phenotypic standard deviations, respectively.

\section{Heritability and genetic advance:}

Heritability in a broad sense $\left(\mathrm{h}^{2} \mathrm{~b}\right)$ for all characters was computed as per the following formula:

$$
\mathrm{h}_{\mathrm{b}}^{2}=\sigma_{\mathrm{g}}^{2} / \sigma_{\mathrm{ph}}^{2} \times 100 .
$$

The genetic advance for selection intensity $(\mathrm{k})$ at $5 \%$ was estimated by the following formula [21,22]:

$$
\mathrm{EGA}=\mathrm{h}_{\mathrm{b}}^{2} / 100 \times \sigma_{\mathrm{ph}} \times \mathrm{k}
$$

where

EGA = the expected genetic advance under selection;

$\sigma_{\mathrm{ph}}=$ the phenotypic standard deviation;

$\mathrm{h}_{\mathrm{b}}^{2}=$ heritability in a broad sense;

$\mathrm{k}=$ selection intensity.

$$
\text { Genetic advance per population mean }=(\text { EGA } / \text { grand mean }) \times 100
$$

\section{Results}

\subsection{Maintainer Lines}

There were highly significant differences among the $216 \mathrm{~F}_{6}$ maintainer lines for all characteristics except angle of floret opening $\left({ }^{\circ}\right)$ and number of tillers per plant (Table 1), thereby indicating that these lines differed significantly for these characteristics. 
Table 1. Analysis of variance of maintainer lines for agronomic and floral traits.

\begin{tabular}{ccccccccc}
\hline \multicolumn{7}{c}{ Agronomic Characteristics } \\
\hline Source of Variation & Degrees of Freedom & DAF & DAM & NPT & PH & GW & GYP \\
\hline Block & 11 & 63.05 & 1898.9 & 8.05 & 255.8 & 0.316 & 277 \\
Lines & 217 & $34.35^{* *}$ & $46.5^{* *}$ & 2.33 NS & $40.73^{* *}$ & $0.11^{* *}$ & $59.16^{* *}$ \\
Error & 11 & 0.678 & 1.041 & 1.5 & 6.06 & 0.01 & 12.56 \\
\hline \multicolumn{7}{c}{ Panicle and Floral Characteristics } \\
\hline Source of Variation & Degrees of Freedom & SE & SOA & PnE & PnL & PnW & NS/Pn & SF\% \\
\hline Block & 11 & 465.1 & 15.62 & 20.5 & 8.58 & 0.758 & 1045.7 & 6.72 \\
Lines & 217 & $278.6^{* *}$ & 12.18 NS & $29.19^{* *}$ & $2.47^{* *}$ & $0.323^{*}$ & $269.4^{* *}$ & $25.21^{*}$ \\
Error & 11 & 10.1 & 6.74 & 0.5 & 0.4 & 0.12 & 26.79 & 10.21 \\
\hline
\end{tabular}

${ }^{*}$ and ${ }^{* *}$ indicate significance at $p \leq 0.05$ and 0.01 , respectively. DAF: number of days to $50 \%$ flowering, DAM: number of days to maturity, NPT: number of tillers per plant, PH: plant height, GW: 1000-grain weight, GYP: grain yield per plant. SE: stigma exertion $(\%)$, SOA: angle of floret opening $\left({ }^{\circ}\right)$, PnE: panicle exertion $(\%)$, PnL: panicle length, PnW: panicle weight, SF: spikelet fertility (\%); NS/Pn: number of spikelet per panicle.

The significant variation for most characteristics revealed the availability of maintainer lines with good agronomic and floral features (Table 2). Days to $50 \%$ flowering ranged between 69 and 108 (average: 97 days), while with the two checks (IR68897B and IR58025B) it was 86 and 104 days, respectively. The days to maturity of the 216 maintainer lines ranged between 83 and 140 (average: 126 days), while it was 118 and 134 for IR68897B and IR58025B, respectively. This large variation of days to $50 \%$ flowering and maturity in the maintainer lines calls for breeding new CMS lines with early, medium, and late maturity. Large variation was also observed for number of tillers per plant (average: $15)$ and plant height $(86 \mathrm{~cm})$. On average, 1000-grain weight and grain yield per plant were $25 \mathrm{~g}$ and $32 \mathrm{~g}$, respectively. A promising maintainer line had $76 \%$ stigma exertion whereas it was $25 \%$ and $30 \%$ for the two checks. The spikelet opening angle ranged between $15.30^{\circ}$ and $37.17^{\circ}$. Both checks and maintainer lines exhibited good panicle exertion, ranging between $78 \%$ and $100 \%$. The average panicle length and panicle weight were $26 \mathrm{~cm}$ and $23 \mathrm{~g}$, respectively. The highest spikelet per panicle was 198 and the lowest was 92 . Spikelet fertility of both maintainer lines and checks was above $73 \%$.

Table 2. Range and average for agronomic and floral characteristics of 216 maintainer lines and two checks.

\begin{tabular}{ccccccc}
\hline Characteristics & Range & Average & IR68897B & IR58025B & LSD $_{\mathbf{0 . 0 5}}$ & CV $^{\mathbf{H}}$ \\
\hline Days to 50\% flowering & $69.46-108.46$ & 96.95 & 85.67 & 104.25 & 1.89 & 0.01 \\
Days to maturity & $83.04-140.54$ & 126.30 & 117.58 & 133.50 & 2.34 & 0.01 \\
Tillers per plant (\#) & $10.87-20.57$ & 15.44 & 17.00 & 18.33 & 2.80 & 0.08 \\
Plant height (cm) & $56.92-104.37$ & 86.44 & 87.25 & 91.09 & 5.65 & 0.03 \\
1000-grain weight (g) & $18.8-33.7$ & 25.3 & 23.70 & 23.00 & 2.20 & 0.40 \\
Grain yield per plant (g) & $10.30-63.11$ & 31.49 & 25.56 & 30.60 & 8.10 & 0.11 \\
Stigma exertion (\%) & $1.13-76.16$ & 30.14 & 24.86 & 29.84 & 7.27 & 0.11 \\
Spikelet opening angle $\left({ }^{\circ}\right)$ & $15.30-36.17$ & 25.64 & 24.84 & 26.67 & 5.95 & 0.10 \\
Panicle exertion $(\%)$ & $78.0-100.0$ & 96.84 & 100.00 & 100.00 & 0.00 & 0.00 \\
Panicle length (cm) & $20.46-29.76$ & 26.06 & 24.45 & 25.64 & 1.47 & 0.02 \\
Panicle weight (g) & $1.79-5.88$ & 3.25 & 3.23 & 3.24 & 0.79 & 0.11 \\
Spikelets per panicle & $91.82-197.67$ & 126.10 & 115.92 & 125.30 & 12.47 & 0.04 \\
Spikelet fertility $(\%)$ & $73.76-97.74$ & 84.78 & 87.54 & 88.09 & 7.28 & 0.04 \\
\hline
\end{tabular}

${ }^{\dagger}$ Coefficient of variation (\%).

\section{Variance and Heritability}

The phenotypic variance was partitioned into genotypic and environmental variances for a clear understanding of the pattern of variation (Table 3). Number of days to maturity exhibited higher environmental variance than genetic variance, while the phenotypic variance of spikelet fertility was 
affected by both environmental and genotypic variances. Overall, the genotypic variance was higher than environmental variance for most characteristics. The phenotypic coefficient of variation (PCV) was close to the genotypic coefficient of variation (GCV) for all characteristics. Stigma exertion and grain yield per plant exhibited the highest estimates of GCV and PCV, followed by panicle weight, spikelet per panicle, 1000-grain weight and spikelet opening angle. The lowest estimates of PCV were for number of days to maturity.

Table 3. Variance components and genetic parameters of agronomic and floral traits of 216 maintainers and two checks.

\begin{tabular}{cccccccc}
\hline Characteristic & $\boldsymbol{\sigma}^{\mathbf{2}} \mathbf{G}$ & $\boldsymbol{\sigma}^{\mathbf{2}} \mathbf{E}$ & $\boldsymbol{\sigma}^{\mathbf{2}} \mathbf{P}$ & $\mathbf{G C V}$ & $\mathbf{P C V}$ & $\mathbf{H}^{\mathbf{2}}$ & $\mathbf{G A}$ \\
\hline Days to 50\% flowering & 27.53 & 0.63 & 28.15 & 5.41 & 5.42 & 75.0 & 11.14 \\
Days to maturity & 6.61 & 35.65 & 42.26 & 2.04 & 2.45 & 69.0 & 3.48 \\
Tillers per plant (\#) & 0.99 & 0.91 & 1.90 & 6.43 & 6.68 & 93.0 & 12.77 \\
Plant height (cm) & 30.32 & 11.45 & 41.77 & 6.37 & 6.47 & 97.0 & 12.92 \\
1000 grain weight (g) & 1.10 & 0.10 & 1.20 & 12.90 & 12.93 & 99.0 & 26.50 \\
Grain yield per plant (g) & 49.58 & 11.60 & 61.18 & 22.36 & 22.57 & 98.0 & 45.62 \\
Stigma exertion (\%) & 295.52 & 5.99 & 301.51 & 57.03 & 57.08 & 97.0 & 117.39 \\
Spikelet opening angle $\left({ }^{\circ}\right)$ & 7.24 & 5.37 & 12.61 & 10.50 & 10.82 & 94.0 & 20.98 \\
Panicle exertion (\%) & 26.72 & 0.12 & 26.84 & 5.24 & 5.34 & 98.0 & 11.00 \\
Panicle length (cm) & 2.07 & 0.35 & 2.41 & 5.52 & 5.56 & 99.0 & 11.29 \\
Panicle weight (g) & 0.23 & 0.11 & 0.34 & 14.75 & 15.04 & 96.0 & 29.81 \\
Spikelets per panicle (\#) & 265.18 & 28.90 & 294.08 & 12.91 & 12.97 & 99.0 & 26.48 \\
Spikelet fertility $(\%)$ & 12.57 & 11.37 & 23.95 & 4.18 & 4.34 & 93.0 & 8.31 \\
\hline
\end{tabular}

$\sigma_{\mathrm{G}}^{2}$ : genotypic variance, $\sigma^{2}{ }_{\mathrm{E}}$ : environmental variance, $\sigma^{2} \mathrm{P}$ : phenotypic variance, $\mathrm{GCV}$ : genotypic coefficient of variation (\%), PCV: phenotypic coefficient of variation, $\mathrm{H}^{2}$ : broad-sense heritability (\%), GA: genetic advance.

Broad-sense heritability estimates were relatively high for all characteristics, thereby suggesting a great genetic advance associated with breeding for agronomic and floral characteristics such as stigma exertion, grain yield per plant, panicle weight, spikelet per panicle, 1000-grain weight and spikelet opening angle. High heritability, associated with high genetic advance, was also noted for duration of floret opening, thus indicating that this characteristic was simply inherited, involving few major genes and likely having additive gene effects.

\subsection{Newly-Bred CMS Lines}

There were highly significant differences among the 17 CMS lines for most characteristics except pollen sterility and panicle sterility during both dry and wet seasons (Table 4). The non-significant differences observed for pollen and spikelet sterility were due to the fact that CMS lines were almost sterile. Only days to $50 \%$ flowering and plant height showed significant differences between the dry and wet seasons. Non-significant interactions were noted among all characteristics except pollen and spikelet fertility.

Data in Table 5 shows the agronomic and floral traits of newly developed CMS lines with two checks. A wide variation range was for noticed for number of days to $50 \%$ flowering; being CMS 13 the earliest (79 days) and IR58028A the latest (98 days). The highest number of tillers per plant was observed for CMS 11 and CMS 12 (18 tillers). Most CMS lines were semi-dwarf for plant height, which ranged between 69 and $91 \mathrm{~cm}$. The semi-dwarf height is a very desirable characteristic in hybrid rice seed production because it facilitates outcrossing to the CMS. Pollen and spikelet sterility were almost $100 \%$ in the 17 CMS lines, thus indicating the stability of this male sterility type. Most of the newly-bred CMS (particularly CMS 3, CMS 12 and CMS 14) had better stigma exertion than the two checks. The spikelet opening angle ranged between $23.33^{\circ}$ and $39.83^{\circ}$, while it was $28.67^{\circ}$ and $29.67^{\circ}$ for the two checks. CMS 2 and CMS 5 were the earliest for spikelet opening time (9:32 a.m.), while CMS 13 was the latest (11:03 a.m.). Except for CMS 13 and CMS 15, the other newly-bred CMS lines exhibited better panicle exertion than the old CMS lines, CMS 3 recorded highest panicle exertion 
(73\%). Outcrossing rates ranged between $22.87 \%$ and 56.17\%. CMS 3, CMS 12, and CMS 14 had the highest outcrossing rates: $56.17 \%, 51.42 \%$, and $48.44 \%$, respectively. We also observed three CMS lines (CMS 3, CMS12, and CMS 14) exhibiting the highest percentages for both stigma and panicle exertion. Broad-sense heritability was relatively high $(>0.85)$ for most agronomic and floral characteristics.

Table 4. Analysis of variance for agronomic and floral traits in 17 newly-bred cytoplasmic male sterility (CMS) lines.

\begin{tabular}{ccccccc}
\hline Source of Variation & DF $^{\boldsymbol{}}$ & DAF & NPT & PH & PS & SpS \\
\hline Replication & 2 & 1.24 & 1.92 & 3.42 & 0.0022 & 0.00005 \\
Line & 16 & $278.12^{* *}$ & $12.01^{* *}$ & $269.90^{* *}$ & 0.0004 & 0.00024 \\
Season & 1 & $10,360.60^{* *}$ & 0.09 & $23.83^{*}$ & 0.0004 & $1.6 \times 10^{-5}$ \\
Season $\times$ Line & 16 & $17.79^{* *}$ & 1.30 & 4.33 & $0.0014^{* *}$ & $0.00182^{* *}$ \\
Residual & 66 & 4.12 & 1.82 & 4.62 & 0.0055 & 0.00050 \\
\hline Source of Variation & DF & SE & SOA & SOT & PnE & OCR \\
\hline Replication & 2 & 11.92 & 3.21 & 0.004 & 18.30 & 3.31 \\
Line & 16 & $1631.90^{* *}$ & $106.60^{* *}$ & $1.800^{* *}$ & $382.90^{* *}$ & $520.90^{* *}$ \\
Season & 1 & 4.96 & 12.50 & 0.004 & 5.99 & 5.52 \\
Season $\times$ Line & 16 & 16.91 & 5.83 & 0.009 & 17.12 & 5.19 \\
Residual & 66 & 25.93 & 8.80 & 0.240 & 15.81 & 6.84 \\
\hline
\end{tabular}

${ }^{*}$ and ${ }^{* *}$ indicate significance at $p \leq 0.05$ and 0.01 , respectively. ${ }^{+}$DF: degrees of freedom, DAF: days to $50 \%$ heading, NPT: number of tiller per plant, PH: plant height, PS: pollen sterility, SpS: spikelet sterility, SE: stigma exertion, SOA: spikelet opening angle $\left({ }^{\circ}\right)$, SOT: spikelet opening time, PnE: panicle exertion, OCR: outcrossing rate.

Table 5. Agronomic and floral traits of 17 newly-bred CMS lines and two checks.

\begin{tabular}{ccccccccccc}
\hline CMS Line & DAF & NPT & PH & PS\% & SpS & SE & SOA & SOT & PnE & OCR \\
\hline CMS 1 & 93.83 & 16.67 & 68.60 & 99.96 & 99.95 & 31.16 & 26.89 & 10.69 & 62.69 & 36.09 \\
CMS 2 & 81.83 & 17.00 & 78.17 & 99.96 & 99.95 & 23.17 & 29.67 & 9.32 & 55.00 & 31.67 \\
CMS 3 & 84.50 & 14.50 & 84.50 & 99.96 & 99.95 & 64.67 & 39.83 & 10.16 & 72.67 & 56.17 \\
CMS 4 & 82.00 & 15.67 & 79.67 & 99.95 & 99.96 & 24.83 & 32.67 & 10.18 & 58.00 & 36.17 \\
CMS 5 & 82.83 & 14.83 & 80.50 & 99.95 & 99.95 & 30.83 & 31.33 & 9.32 & 65.67 & 38.33 \\
CMS 6 & 84.00 & 15.50 & 85.50 & 99.94 & 99.95 & 33.67 & 34.50 & 9.48 & 65.83 & 40.83 \\
CMS 7 & 85.00 & 15.17 & 89.17 & 99.94 & 99.94 & 40.67 & 35.00 & 9.68 & 70.33 & 44.00 \\
CMS 8 & 87.33 & 14.17 & 89.00 & 99.95 & 99.95 & 42.33 & 34.50 & 10.25 & 67.00 & 43.33 \\
CMS 9 & 86.83 & 14.33 & 85.67 & 99.96 & 99.96 & 51.28 & 34.17 & 10.20 & 70.50 & 45.67 \\
CMS 10 & 94.00 & 16.67 & 80.27 & 99.96 & 99.95 & 19.15 & 26.30 & 10.79 & 58.25 & 32.28 \\
CMS 11 & 96.50 & 18.00 & 88.47 & 99.95 & 99.94 & 19.01 & 26.93 & 10.58 & 55.27 & 30.31 \\
CMS12 & 88.67 & 18.00 & 74.13 & 99.95 & 99.95 & 58.98 & 31.50 & 10.43 & 69.10 & 51.42 \\
CMS 13 & 78.50 & 13.83 & 78.37 & 99.94 & 99.95 & 19.69 & 25.47 & 11.03 & 50.87 & 26.87 \\
CMS14 & 97.33 & 17.50 & 90.55 & 99.94 & 99.94 & 53.61 & 29.83 & 10.43 & 69.54 & 48.44 \\
CMS 15 & 86.33 & 17.67 & 69.50 & 99.95 & 99.95 & 9.13 & 23.33 & 10.87 & 47.96 & 22.87 \\
IR58025A & 97.67 & 17.17 & 75.60 & 99.96 & 99.96 & 19.79 & 28.67 & 9.92 & 51.72 & 27.55 \\
IR68897A & 79.50 & 15.50 & 78.17 & 99.97 & 99.96 & 16.00 & 29.67 & 9.38 & 54.33 & 31.83 \\
\hline Standard Error & 1.15 & 1.11 & 1,71 & 0.02 & 0.14 & 4.13 & 2.41 & 0.17 & 3.17 & 2.06 \\
LSD 0.05 & 1.82 & 1.86 & 2.45 & 0.32 & 0.26 & 7.18 & 4.32 & 0.24 & 6.43 & 3.99 \\
\hline
\end{tabular}

DAF: days to 50\% heading, NPT: number of tillers per plant, PH: plant height, PS: pollen sterility (\%), SpS: spikelet sterility (\%), SE: stigma exertion (\%), SOA: spikelet opening angle $\left({ }^{\circ}\right)$, SOT: spikelet opening time, PnE = panicle exertion $(\%), \mathrm{OCR}=$ outcrossing rate $(\%)$.

Highly significant positive correlations were observed between DAF and NTP $(r=0.70)$, pollen and spikelet sterility $(r=0.62)$, Table 6 . Stigma exertion and plant height $(r=0.42)$, and SOA with both SE $(r=0.75)$ and PnE (0.79). Likewise, outcrossing rates had a highly significant positive correlation with SE (0.97), SOA $(r=0.82)$, and $\operatorname{PnE}(r=0.95)$. Moreover, there was a significantly positive correlation between PnE and PH $(r=0.54)$. We also observed a highly significant positive correlation between pollen and spikelet sterility $(r=0.62)$. 
Table 6. Correlation coefficients between agronomic and floral characteristics in 17 CMS lines.

\begin{tabular}{cccccccccc}
\hline & NPT & PH & PS & SpS & SE & SOA & SOT & PnE & OCR \\
\hline DAF & $0.70^{* *}$ & -0.026 & -0.089 & -0.058 & 0.22 & -0.23 & 0.39 & 0.14 & 0.15 \\
NPT & & -0.33 & -0.067 & -0.033 & -0.21 & -0.52 & 0.2 & -0.31 & -0.24 \\
PH & & & -0.29 & -0.52 & $0.42^{* *}$ & 0.56 & -0.22 & $0.54^{*}$ & 0.48 \\
PS & & & & $0.62^{* *}$ & -0.16 & 0.031 & -0.19 & -0.16 & -0.14 \\
SpS & & & & & -0.21 & -0.1 & -0.16 & -0.31 & -0.26 \\
SE & & & & & & $0.75^{* *}$ & -0.051 & $0.92^{* *}$ & $0.97^{* *}$ \\
SOA & & & & & & & -0.49 & $0.79^{* *}$ & $0.82^{* *}$ \\
SOT & & & & & & & & -0.21 & -0.16 \\
PnE & & & & & & & & & $0.95^{* *}$ \\
\hline
\end{tabular}

${ }^{*}$ and ${ }^{* *}$ indicate significance at $p \leq 0.05$ and 0.01 , respectively. DAF: days to 50\% heading, NPT: number of tiller per plant, PH: plant height, PS: pollen sterility, SpS: spikelet sterility, SE: stigma exertion, SOA: spikelet opening angle, SOT: spikelet opening time, PnE: panicle exertion, OCR: outcrossing rate.

\section{Discussion}

Low seed set remains a major challenge in hybrid seed production for rice. Improvement of floral characteristics, especially stigma and panicle exertion, of CMS lines is very important to improving outcrossing rates and increasing seed set for producing hybrid seed. This requires us to develop maintainer lines with desired floral and agronomic characteristics and transfer CMS through backcrossing. We were able to breed new CMS lines with outcrossing rates above $50 \%$. Out of 216 maintainer lines evaluated for floral and agronomic characteristics, 16 were selected for further use in breeding.

There were highly significant differences among the $216 \mathrm{~F}_{6}$ maintainer lines for all characteristics except angle of floret opening $\left({ }^{\circ}\right)$ and number of tillers per plant, thus indicating that these lines differed significantly for most desired traits. Similar results were obtained by the authors of [23], who found highly significant differences for various traits among 11 genotypes. Significant variation was observed for all characteristics, which provides a source for further breeding of maintainer lines combining the desired agronomic and floral characteristics. The large variation in days to $50 \%$ flowering and maturity of maintainers and CMS is very important to optimize the synchronization of flowering with restorer lines of different duration in hybrid seed production. The ratio of GCV to PCV was high, thus indicating that most of the phenotypic expression of the agronomic and floral characteristics was due to genetics. This finding suggests the potential for genetic gains due to selection for these traits in such CMS lines of rice. The results also indicated significant genetic variability among the tested maintainer lines for most characteristics, which agreed with previous research $[24,25]$. Broad-sense heritability estimates were relatively high for all characteristics, thereby indicating that selection of superior genotypes based on phenotypic performance should be very effective. [26]. The high heritability estimates along with high genetic advance should allow for selecting the best offspring among CMS lines, which also agreed with previous results elsewhere $[27,28]$. Low heritability estimates along with low genetic advance reveal a non-additive type of gene action and significant genotype $\times$ environment interaction affecting the expression of characteristics [25,28,29].

The newly-bred CMS lines exhibited highly significant differences for most characteristics. Most of them exhibited desirable traits vis-à-vis the two checks. The high outcrossing rate associated with high stigma and panicle exertion indicated that selection for such floral characteristics along with spikelet angle opening could be efficient for improving outcrossing rates. These results agreed with previous research [12,30], in which natural outcrossing rates ranged from 14.8 to $51 \%$, while 14 of our newly developed CMS lines had an outcrossing rate above $35 \%$. Our results suggest that additive genes play a major effect on floral and agronomic characteristics, thus being selected in earlier generations was very effective, as noted previously by Tian et al. [29].

Highly significant positive correlations were observed between different traits with outcrossing rates, as also found elsewhere [31-33]. This finding suggests that indirect selection to increase 
outcrossing rates may be effective in our breeding population for hybrid rice. A high panicle exertion in CMS lines was essential to attain high outcrossing rates, as noted previously [34]. Plant height, panicles per plant, and panicle length should also be regarded as very important for enhancing outcrossing rates in rice [35].

\section{Conclusions}

Hybrid seed production is the key to success in the breeding and cultivation of hybrid rice. The adoption of hybrid rice is severely limited, primarily because of its higher seed cost due to low hybrid seed set. Understanding the genetic variability of floral and agronomic characteristics is very important for improving hybrid seed set in rice. Evaluation and selection of maintainer lines with good floral and agronomic characteristics was the first step in developing new CMS lines with high outcrossing rates. High genotypic variance and high heritability estimates along with high genetic advance suggest the potential for selecting the best offspring as CMS lines. In this study three newly-bred CMS lines (namely, CMS 3, CMS 12, and CMS 14) were the best and had the highest outcrossing rates. Their high panicle and stigma exertion (Figure 2) are very important floral characteristics to achieve a suitable outcrossing rate for hybrid seed production in rice, while their outstanding agronomic traits will be necessary to obtain both high seed set and grain yield.
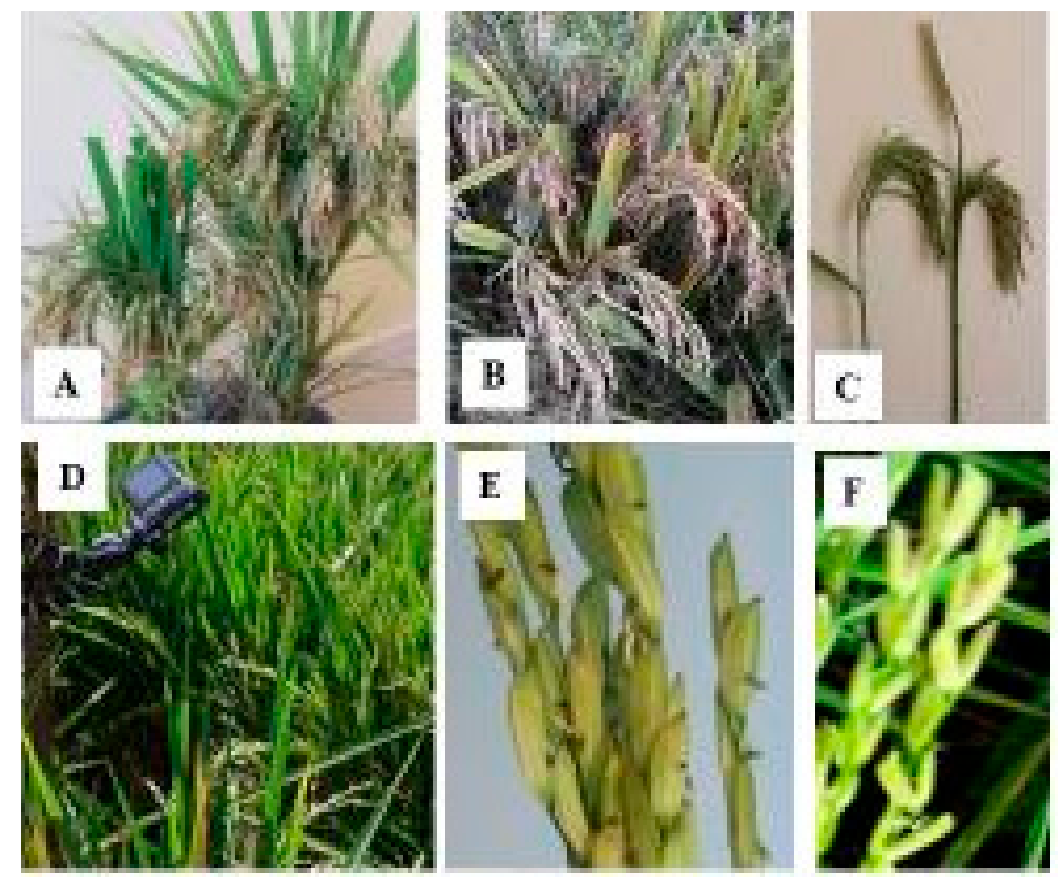

Figure 2. Improved floral and agronomic characteristics of newly-bred CMS lines. (A) Good agronomic traits of CMS line; (B) high outcrossing rate of improved CMS line as a result of desired floral characteristics; (C) good panicle exertion for CMS (left side) and maintainer lines (right side); (D) the use of a digital camera to record spikelet characteristics; (E) good stigma exertion for newly-bred CMS lines; (F) large glume opening of newly-bred CMS line.

Author Contributions: R.E.-N. conceived and designed the experiments; performed the experiments; analyzed the data; contributed reagents/materials/analysis tools and wrote the paper.

Acknowledgments: The author thanks Rodomiro Ortiz (Swedish University of Agricultural Sciences) for his advice during the writing of this manuscript. This research was possible due to grant funding from various sources to AfricaRice.

Conflicts of Interest: The author declares no conflict of interest. 


\section{References}

1. El-Namaky, R.; Nwilene, F.; Coulibaly, M.B.; Alhassan, M.; Traore, K.; Dieng, I.; Ortiz, R.; Manneh, B. Putting plant genetic diversity and variability at work for breeding: Hybrid rice suitability in West Africa. Diversity 2017, 9, 27. [CrossRef]

2. Duvick, D.N. Heterosis: Feeding people and protecting natural resources. In Genetics and Exploitation of Heterosis; Coors, J.G., Pandey, S., Eds.; American Society of Agronomy-Crop Science Society of America: Madison, WI, USA, 1999; pp. 19-24. ISBN 9780891185499.

3. Li, S.; Yang, D.; Zhu, Y. Characterization and Use of Male Sterility in Hybrid Rice Breeding. J. Integr. Plant Biol. 2007, 49, 791-804. [CrossRef]

4. Guo, L.; Zhuang, J.; Qiu, F.; Gandhi, H.; Kadaru, S.; Jon, E.; Asis, D.; Xie, F. Genome-wide association study of outcrossing in cytoplasmic male sterile lines of rice. Sci. Rep. 2017, 7, 3223. [CrossRef] [PubMed]

5. Jain, M.; Kaur, R.; Yadav, S.S. Phenotypic characterization of new cytoplasmic male sterile lines in rice (Oryza sativa L.). J. Pharmacogn. Phytochem. 2017, 6, 166-167.

6. Ma, X.; Zheng, Z.; Lin, F.; Ge, T.; Sun, H. Genetic analysis and gene mapping of a low stigma exposed mutant gene by high throughput sequencing. PLoS ONE 2018, 13, e0186942. [CrossRef] [PubMed]

7. Zhou, H.; Li, P.B.; Xie, W.B.; Hussain, S.; Li, Y.B.; Xia, D. Genome-wide association analyses reveal the genetic basis of stigma exertion in rice. Mol. Plant 2017, 10, 634-644. [CrossRef] [PubMed]

8. Parmar, K.S.; Swaminathan, M.S.; Siddiq, E.A. Variation in reproductive organs of rice with reference to male incompatibility index. Indian J. Genet. Plant Breed. 1980, 40, 262-271.

9. Virmani, S.S.; Khush, G.S.; Yang, R.C. Rice cultivars possessing some desirable floral traits influencing outcrossing. Int. Rice Res. Newsl. 1980, 5, 4-5.

10. Sarkar, H.C.; Miah, N.M. Extent of natural outcrossing of V20a, a cytoplasmic male-sterile (CMS) line in Bangladesh. Int. Rice Res. Newsl. 1983, 8, 7-8.

11. Taillebois, J. New prospects for the production of $F_{1}$ hybrid seed: Transfer of allogamous characters of O. longistaminata A. Chev. to O. sativa L. Agron. Trop. Nogent 1983, 38, 303-307.

12. Pandey, P.; Tiwari, D.K.; Dwivedi, J.L. Evaluation of CMS lines for different allogamic traits that influence out crossing in rice (Oryza sativa L.). AAB Bioflux 2010, 2, 247-250.

13. Li, T.; Chen, Y. Genetics of stigma exertion in rice. Rice Genet. Newsl. 1985, 2, 84-85.

14. El-Namaky, R.A.; Demont, M. Hybrid rice in Africa: Challenges and prospects. In Realizing Africa's Rice Promise; Wopereis, M.C.S., Ed.; CAB International: Wallingford, UK, 2013; pp. 173-178. ISBN 9781845938123.

15. El-Namaky, R.; Van Oort, P. Phenology, sterility and inheritance of two environment genic male sterile (EGMS) lines for hybrid rice. Rice 2017, 10, 31. [CrossRef] [PubMed]

16. Gomez, K.A.; Gomez, A.A. Statistical Procedures for Agricultural Research, 2nd ed.; John Wiley \& Sons: New York, NY, USA, 1983; p. 690. ISBN 0471-87092-7.

17. Yang, B. Study on stigma exertion rate of sterile line and its seed setting rate. Hybrid Rice 1997, 12, $13-15$.

18. IRRI. Standard Evaluation System for Rice; International Rice Research Institute: Los Baños, Philippines, 2014; ISBN 9712203042.

19. Burton, G.W.; Devane, E.M. Genetic variability, correlation and path coefficient analysis in rice. Agron. J. 1953, 45, 478-481. [CrossRef]

20. Dilnesaw, Z.; Abadi, S.; Getahun, A. Genetic variability and heritability of soybean (Glycine max (L.) Merrill) genotypes in Pawe district, Metekel zone, Benishangule Gumuz regional state, Northwestern Ethiopia. Wudpecker J. Agric. Res. 2013, 2, 240-245.

21. Hanson, C.H.; Robinson, H.F.; Comstock, R.E. Biometrical studies of yield in segregating populations of Korean Lespedeza. Agron. J. 1956, 48, 268-272. [CrossRef]

22. Jonson, H.W.; Robinson, H.F.; Comstock, R.E. Estimates of genetic and environmental variability in soybean. Agron. J. 1955, 47, 314-318. [CrossRef]

23. Robinson, H.F.; Akkaya, M.S.; Bhagwat, A.A.; Lavi, V.; Cregan, P.B. Estimation of genetic variability, heritability and genetic advance in "new plant type" tropical japonica rice under upland environment. Agron. J. 1951, 43, 262-267.

24. Savitha, P.; Kumari, U.R.; Vanniarajan, C. Correlation between selected morphological character and yield components related traits in Oryza sativa L. Indian J. Exp. Biol. 2017, 55, 642-647. 
25. Majumder, R.R.; Roy, R.K.; Kader, M.A.; Aditya, T.L.; Ansari, A. Variability, correlation and path analysis in maintainer lines of aromatic rice for outcrossing traits. Bangladesh J. Crop Sci. 2013, 25, 139-146.

26. Singh, R.K.; Chowdhury, B.D. Variability, heritability, and genetic advance in cultivars of rice (Oryza sativa L.). Crop Res. Hisar 1996, 12, 165-167.

27. Iftekharuddaula, K.M.; Hasan, M.S.; Islam, M.J.; Badshah, M.A.; Islam, M.R.; Khaleda, A. Genetic evaluation and selection criteria of hybrid rice in irrigated ecosystem of Bangladesh. Pak. J. Biol. Sci. 2001, 4, 790-792.

28. Khaleda, A.; Iftekharuddaula, K.M.; Basar, M.K.; Kabir, M.H.; Sarkar, M.Z.A. Genetic variability, correlation and path analysis in irrigated hybrid rice. J. Subtrop. Agric. Res. Dev. 2004, 2, 17-23.

29. Hossain, M.A.; Mianm, A.K.; Rasul, M.G.; Hasan, M.J.; Kulsum, M.U.; Karim, M.A. Genetic variability in floral Traits of CMS lines and their relationship with outcrossing in rice. Trop. Agric. Dev. 2016, 60, $236-241$.

30. Virmani, S.S.; Athwal, D.S. Genetic variability for floral characters influencing outcrossing in Oryza sativa L. Crop Sci. 1973, 13, 66-67. [CrossRef]

31. Tian, D.; Zhang, S.; Qin, C. Increase of stigma exertion rate is the key measure for high yielding in hybrid seed production of rice. Sichuan Agric. Sci. Technol. 1990, 2, 16-18.

32. Dai, G.; Hua, Z.; Cai, W. Study on application of hormone in seed production of japonica hybrid rice. Hybrid Rice 1999, 14, 15-20.

33. Kato, H.; Namai, H. Intervarietal variations of floral characteristics with special reference to $F_{1}$ seed production in japonica rice (Oryza sativa L.). Jpn. J. Breed. 1987, 37, 75-87. [CrossRef]

34. Virmani, S.S. Outcrossing mechanisms and hybrid seed production practices in rice. In Heterosis and Hybrid Rice Breeding; Springer Verlag-International Rice Research Institute: Manila, Philippines, 1994; pp. 79-96.

35. Li, Q.L.; Lt, G.T.; Guo, G.Z.; Jiang, G.; Zhu, Y. Study on high yield breeding and genetic analysis of yield components of main rice cultivars in Jilin. Inst. Agric. Sci. 1991, 13, 3-6.

(C) 2018 by the author. Licensee MDPI, Basel, Switzerland. This article is an open access article distributed under the terms and conditions of the Creative Commons Attribution (CC BY) license (http:/ / creativecommons.org/licenses/by/4.0/). 